Santa Clara University

Scholar Commons

Psychology

College of Arts \& Sciences

$10-1998$

\title{
Social support in marriage: Translating research into practical applications for clinicians
}

Kieran T. Sullivan

SantaClara University, ksullivan@scu.edu

Lauri A. Pasch

Kathleen A. Eldridge

Thomas N. Bradbury

Follow this and additional works at: http://scholarcommons.scu.edu/psych

Part of the Psychology Commons

\section{Recommended Citation}

Sullivan, K.T., Pasch, L.A., Eldridge, K.A., \& Bradbury, T.N. (1998). Social support in marriage: Translating research into practical applications for clinicians. The Family Journal, 6, 263-271.

http://doi.org/10.1177/1066480798064002

This Article is brought to you for free and open access by the College of Arts \& Sciences at Scholar Commons. It has been accepted for inclusion in Psychology by an authorized administrator of Scholar Commons. For more information, please contact rscroggin@scu.edu. 
Running Head: SOCIAL SUPPORT IN MARRIAGE

Social Support in Marriage:

Translating Research into Practical Applications for Clinicians

\author{
Kieran T. Sullivan \\ Santa Clara University \\ Lauri A. Pasch \\ University of California, San Francisco \\ Kathleen A. Eldridge Thomas N. Bradbury \\ University of California, Los Angeles
}


Abstract

How spouses support one another may be important in understanding and preventing marital distress, but has received relatively little attention. Instead, the behavioral model of marriage and corresponding treatment protocols have focused on the importance of good conflict management skills in preventing and treating marital distress. This paper outlines recent research indicating that couples social support skills predict marital outcome two years later, above and beyond conflict management skills. These results indicate that successful prevention and treatment programs may need to incorporate support skills training as well as conflict management training. Practical implications of this research are outlined, and specific techniques are recommended for teaching social support skills to couples. 
Social Support in Marriage: 
Translating Research into Practical Applications for Clinicians

Virtually all marital research and clinical interventions designed to improve marital quality have been geared toward understanding how couples resolve marital difficulties. Very little attention has been given to how couples support and help one another. The lack of attention to social support in marriage may be a significant oversight in our understanding of the development of marital distress. In this paper, we first provide a brief review of the literature on couples communication and make a case for expanding the focus of research beyond conflict to include social support. We then provide a synopsis of our research findings regarding the importance of social support in the development of marital distress. Finally, we discuss the practical implications of this research for practitioners, specifically addressing the question of what we can do when working with couples to enhance their ability to ask for and provide support to each other.

Expanding the focus on marital research beyond conflict resolution skills

Most research on marital functioning has focused on conflict, especially on how couples behave when discussing conflictual issues with one another. In this approach, marital distress "is assumed to be a function of couples interaction patterns. Inevitably couples have wants and needs that conflict. Distress results from couples’ aversive and ineffectual response to conflict.” (Koerner \& Jacobson, 1994, p. 208). In other words, the assumption has been that marital distress can best be understood by understanding how couples handle conflict and therefore marital distress can best be alleviated by increasing couples' skills in resolving conflicts between them.

The focus on skills for handling conflict has led to some important findings that have advanced our understanding of marriage and informed our clinical interventions. One general 
Social Support in Marriage 5

finding across many studies has been that positive conflict management behaviors do not seem to be associated with marital satisfaction. Instead, research has indicated that maritally distressed couples are more likely to engage in negative behavior, to reciprocate negative behavior, and to remain longer in cycles of negative reciprocity when compared to happily married couples (for a review see Weiss \& Heyman, 1990). The information gained from this research has guided the development of intervention protocols. In particular, the behavioral marital therapy approach is based in large part on improving couples' skills in conflict management (Jacobson \& Margolin, 1979). 
However, one important limitation of the research on conflict resolution skills is that most of the studies are cross-sectional, comparing the communication of distressed couples and nondistressed couples at one point in time. Differences between distressed and nondistressed couples may have been due to the fact that, when asked to pick a topic they disagree about, distressed couples tend to pick larger or more significant marital problems than nondistressed couples. In other words, the relatively higher levels of negative behavior displayed in distressed couples interactions may not have been due to how they were arguing, but due to what they were arguing about. This conflict-topic confound is probably impossible to control for in crosssectional research because the nature of the topic is closely tied to nature of the behaviors that the couple displays while discussing the topic. 
Longitudinal research on marital communication overcomes this problem to an extent, because the baseline level of marital distress can be controlled in predicting later distress. Longitudinal studies can suggest interaction styles that may foreshadow the development of distress, as opposed to reflecting the level of distress. Such studies have found associations between observed conflict management behavior and change in marital quality (e.g., Bradbury \& Fincham, 1991; Markman, 1981), however the effects have not been all that strong. According to a recent meta-analysis of all longitudinal studies on marriage, only about $10 \%$ or less of the variance in change in satisfaction was accounted for by negative behaviors (Karney \& Bradbury, 1995). For practitioners, this indicates that teaching couples to be less negative when discussing conflictual issues may not be very powerful in helping couples stay happy over time. Theoretically, this seems to indicate that there is more going on than we are measuring. Communication skills in other domains may account for at least some of the remaining variance. A recent longitudinal study of couples who participated in the Premarital Relationship Enhancement Program (PREP; Hahlweg et. al, 1996) in Germany confirms that changes in negative conflict resolution behaviors do not really help much in preventing deterioration over time. In this study, researchers measured couples' conflict resolution skills before and after they received PREP or a control condition. In addition, they measured the couples' marital satisfaction 5 years later. Before the intervention, couples in the treatment group and couples in the control group displayed about the same amount of negative and positive behavior when discussing conflictual topics. After the intervention, the treatment couples showed significantly less negative behaviors when discussing conflict topics than control couples. However, there was very little difference in marital satisfaction between the groups 5 years later. It seems that teaching couples better conflict resolution skills does not necessarily mean they will be less 
likely to become distressed down the line. 
Why consider social support? 
Social Support in Marriage 10

Social support in the context of marriage includes spouses' efforts to fulfill the immediate needs of their partner engendered by stressful life events as well as the cumulative benefits of supportive interactions such as a sense of security and self-efficacy. Cutrona (1996) defines social support as follows, "Social support is conceptualized most generally as responsiveness to another's needs and more specifically as acts that communicate caring; that validate the other's words, feelings or actions; or that facilitate adaptive coping with problems through the provision of information, assistance, or tangible resources" (p.10). When this kind of responsivity to the other's needs is consistent over time, it fosters love, trust, tolerance, and commitment, elements that contribute to the stability of intimate relationships. 
Social Support in Marriage 11

Spouses' abilities to communicate in the context of providing and receiving support is an unexplored but potentially important domain for understanding what leads marriages to succeed and fail. We believe that support communication is worthy of close attention for several reasons. First, studying couples’ communication only when they are in conflict with one another fails to take into account factors outside the marriage that may affect the marital relationship. In order to understand how marriages change from being very happy in the beginning to ending in separation or divorce, it is important to study couples in the context of their environment. Particularly, we need to take into account the stresses and pressures that spouses deal with in their individual lives, how they bring those stressors into the relationship, and how the couple then copes with the individual distress of each partner. 
Second, examining spouses' skills in soliciting support from and providing support to one another may be especially important when studying newlywed marriage. In fact, many newlyweds say that the main reason they marry is for friendship and support. People often choose to marry someone who they feel they can really talk to, with whom they can share life's ups and downs. In fact, newlyweds interactions are typically supportive discussions about the difficulties and frustrations that each encounter in their lives outside the marriage. Conflict discussions, in contrast, are relatively rare for newlyweds. So studying communication during supportive interactions may give us a more accurate view of newlyweds' actual daily interactions and behaviors. 
Social Support in Marriage

There has been a recent growth of interest in studying social support in marriage and particularly how skills in support provision and receipt may influence the ongoing functioning of the marriage (e.g., Cutrona \& Suhr, 1994). In the next section, we outline some findings from our research on how social support operates in marriage. 
Social support in marriage: Overview of recent findings

To understand how spouses’ social support behavior affects change in marriage over time, we conducted a study following newlyweds through the first $2 \frac{1}{2}$ years of their marriage. Sixty couples were recruited via newspaper advertisements to participate in a research project on newlywed marriage. All couples were married for the first time, for less than 6 months, and had no children. Husbands averaged 25.4 years of age $(S D=3.4), 15.6$ years of formal education ( $\underline{\mathrm{SD}}=2.2$ ), and had a modal gross annual income between $\$ 11,000$ and $\$ 20,000$; wives averaged 24.0 years of age $(\mathrm{SD}=2.9), 15.6$ years of formal education $(\underline{\mathrm{SD}}=1.6)$, and also had a modal gross annual income between $\$ 11,000$ and $\$ 20,000$. Seventy-five percent of the sample were Caucasian, 10\% were Hispanic, 7\% were Asian, 5\% were African-American, and 3\% indicated "Other” for their race.

Couples participated in a laboratory session in which they provided demographic and questionnaire data and participated in one 15-minute problem-solving discussion and two 10minute social support discussions. The problem-solving discussions were coded later using the Specific Affect Coding System (SPAFF; see Gottman \& Krokoff, 1989). This system identifies particular affects that couples displayed; the analyses presented here were based on summary codes of positive (displays of humor and affection) and negative (anger and contempt), which capture $85-95 \%$ of variation in all the codes that are available. The social support discussions were coded using the Social Support Interaction Coding System (SSICS; Bradbury \& Pasch, 1992). Codes for both discussions had adequate reliability, with interclass correlations ranging from .80 to .99 across all codes (see Pasch \& Bradbury, 1998 for more detail). 
Social Support Task. For the social support discussions, couples were asked to have two 10-minute discussions, one in which the husband would discuss a personal problem (as the "helpee”) and the wife would respond (as the "helper”) and one in which the wife would discuss a personal problem and the husband would respond. The couples were instructed to "talk with [their spouse] about something you would like to change about yourself. This could be about almost anything, like your work habits, your career, something about your personality or your appearance, some problem you have, friendships or relationships within your family - and the important thing is that whatever you discuss is something you want to change about yourself, and that it is not really a problem in your marriage - it should be more of a personal thing that you want to change.” Common topics that spouses chose included losing weight, handling stress better, being more assertive, learning to worry less, managing their time better, clarifying career decisions and goals, and forming new friendships. 
These discussions were taped and later coded using the SSICS. In this system, behavior is coded as either positive, negative, neutral or off-task. In addition, three types of positive codes were used, positive instrumental (used for practical suggestions or questions), positive emotional (used for comments acknowledging the emotional dimension of the problem), and positive other (used for positive behaviors that are not specifically instrumental or emotional). An example of a positive instrumental code is, "OK, so tomorrow, when you see Jack, what are you going to ask him?” An example of a positive emotional code is, "I know this is hard for you, you really loved that job and it was hard to leave.” An example of a positive other code is, "We've been thinking of this as a self-esteem problem, when maybe it has something to do with the environment of your job”. Examples of negative helper codes are "If you went to community college, I doubt you'd be able to get past the first class," or "So what used to be your problem is now my problem.” Neutral codes were used for all behaviors that related to the issue at hand but were not positive or negative. Off-task codes were used for behaviors that involve matters not relevant to the problem under consideration (e.g., “So where do you want to eat tonight?”).

The helpee's behavior was coded as positive, negative, neutral or off-task. An example of positive helpee behavior is, "I just feel so much better when I talk about this with you and you say 'you were meant for this type of work.'” Examples of negative helpee behavior are, “You've just got to help me with this, tell me what to do," or “You're really not doing much good for me here, you're really not being very helpful.”

Marital Satisfaction. Marital satisfaction was measured using the 15-item Marital Adjustment Test (MAT; Locke \& Wallace, 1959), a widely used self-report measure commonly accepted as an adequate index of marital satisfaction with high reliability demonstrated across many studies (split half $=.90$ ). The MAT was administered at the initial laboratory session and 
again at the 24-month follow-up. Initial mean MAT scores were $120.4(\underline{\mathrm{SD}}=17.4)$ for husbands and 119.7 ( $\underline{\mathrm{SD}}=17.3)$ for wives. As expected for newlyweds, these means were well above the commonly accepted cut-off of 100 points to differentiate distressed from nondistressed couples.

$\underline{\text { Results. }}$ To determine whether communication behavior affected marital outcome, the couples were divided into three groups based on their 24-month MAT scores. Couples with average MAT scores less than 90 were designated distressed, and the scores of the remaining couples were divided in half to form satisfied and very satisfied groups. The association between problem-solving discussions and marital outcome can be seen on Figure $1{ }^{1}$ Consistent with previous studies, positive behavior did not appear to differentiate among outcome groups. However, negative behavior did differentiate distressed couples from satisfied and very satisfied couples. Couples who became distressed were about two to three times more likely to display negative behavior in their original problem-solving discussions. Negative behavior did not seem to differentiate between satisfied and very satisfied couples.

The association between social support behavior and marital outcome can be seen on Figures 2 and 3. Here, distressed couples were significantly less positive and more negative when acting as helpee than nondistressed couples, especially wives (see Figure 2). When acting as helpers, husbands and wives in the distressed group were less positive and more negative than nondistressed husbands and wives (see Figure 3). In fact, for wives, distressed helpers were three times as likely to be negative in their social support discussions two years earlier than nondistressed helpers. So we see that even in a very different type of discussion (and a much more positive type of discussion), skills deficits are still predictive of marital outcome. As stated by Pasch and Bradbury (in press), "the behavioral deficits that predict deterioration in marital functioning are not unique to conflict resolution skills, nor are conflict resolution skills uniquely 
important.” It appears that if we want to more fully understand what behaviors lead to distress and divorce, we must take into account support behaviors as well as conflict behaviors. These implications are further supported by a preliminary analysis of a larger data set (based on 172 newlyweds recruited via marriage licenses) that reveal very similar associations between the two types of discussions and marital outcome.

These data indicate that problem-solving and social support discussion tasks appear to elicit related but distinct forms of marital behavior, across which, the same basic pattern emerges. Higher rates of negative behavior, and to a lesser extent lower rates of positive behavior, are associated with poorer marital outcome. Thus the link between poorer communication and adverse marital outcome is not confined to the domain of problem-solving. The immediate and perhaps most important practical implication of this finding is that enhancing couples social support skills, especially in conjunction with their problem-solving skills may lead to more effective and lasting interventions with couples. A secondary implication is that teaching social support skills may be somewhat different than teaching problem-solving skills. Conflict training tends to involve teaching couples to be better adversaries. Social support training tends to involve teaching couples to be a better team and to focus on how they can cope, as a team, with the stressors that the world sends them.

\section{$\underline{\text { Strategies for helping couples to enhance social support in their marriages }}$}

Perhaps the most useful starting point in helping couples to enhance social support in their marriages is to educate them on what social support is and why it is important for their relationship. Couples participating in prevention or enrichment programs and especially couples who are seeking marital treatment are more likely to be motivated to resolve conflict and relatively unfocused on the long term importance of good support skills to their relationships. 
This section will begin by highlighting important concepts to educate couples about, followed by general suggestions for helping couples to enhance social support in their marriages. Finally, specific techniques for working with couples will be suggested (also see Cutrona, 1996). Educating couples about social support

Help couples become aware of the nature and importance of social support in their marriage. Couples probably already have an innate sense of the importance of support in their marriage. When asked, many couples will say that they married because they were such good friends or because they could really talk to one another. Emphasize to couples the importance of staying focused on friendship and support for their long term satisfaction and that support skills are something they can work on and enhance.

Help couples recognize the different tasks involved in seeking and receiving help. Research indicates that different skills are required to effectively solicit support from a partner and to effectively give support to their partner. Couples need to recognize that these roles are different and that they can do each one well.

Help couples to see that a supportive climate in marriage is likely to enhance their problem-solving. This may be especially important when working with distressed couples who are primarily concerned with conflicts in their relationship. Couples may be more motivated to work on support skills when they realize that such skills will also help to reduce their level of conflict. If partner's needs for support for individual distress are taken care of, this may help get them on an emotional neutral ground, which will make them better prepared to handle couple conflicts that arise. In addition, distressed partners may initially be unable to engage in the collaboration and compromise that are required for effective problem-solving. Social support training may help prepare them to begin to handle their conflicts in a better way. 
Help couples realize that they can be better givers and recipients of social support. We teach spouses that they can improve their conflict resolution skills, we also need to teach them that their abilities to give and receive support can also be improved. In fact, it may even be easier to bring about change in social support skills than conflict resolution skills, because first, support discussions do not involve the intense affect that usually accompanies marital conflicts. Second, support discussions do not usually involve marital issues. Third, people can appreciate the benefits of getting good support themselves and see the positive benefits of support for their partner.

General suggestions for enhancing social support

Help spouses to understand what kind of support their spouses prefer and how this might be different from what they like. Differences in preferences for types of support (e.g., emotional validation, practical suggestions, etc.) may be due to differences in partner's family of origin, gender differences, differences in personality, or many other factors. Preferences may even change with time and by situation. It is important for partners to recognize which type of approach works for them and for their partner and that these approaches may differ. When attempting to provide support, simply giving their partner the type of support that feels good to them may not be enough. Spouses need to learn what works for their partner and use those techniques when their partner is in distress. When asking for support, spouses need to learn how to approach their partner in a way that optimizes their chances of obtaining the kind of support they would like.

Help spouses recognize the effects of negative behavior when their partner is distressed or vulnerable. Approaching their partner for help or support can make spouses feel very vulnerable. Often sharing about things that are very disturbing entails really opening up and 
revealing who we are. Spouses need to recognize that a negative response in such moments can be devastating to their partner and can adversely affect the marriage. Indeed, a large literature shows that spouses' ability to discount negative actions by the partner is characteristic of better marriages (for a review, see Bradbury \& Fincham, 1990), and it seems likely that this would hold for partner stress and tension.

Help spouses to see that their partner's behavior is affected by circumstances outside of his or her control. It is important for spouses to keep in mind that we do operate in a stressful world and that we do have difficult things happening to us, maybe not everyday, but quite commonly. It may help spouses to realize that the reason why their partner is coming to them and feeling somewhat distressed does not necessarily have a lot to do with who their partner is, but rather with the kind of environment that they are operating in. This can help spouses to avoid blaming their partner and enable them to feel more like their partner deserves support.

Help spouses to see the value in containing and managing some of their own distress. Spouses need to recognize that it is unrealistic and perhaps detrimental to expect that their partners should always be there to support them whenever they are in distress. Their partner may not be available, physically or emotionally, or their partner may not be the appropriate person to help with a particular problem, sometimes a friend or an expert may be the more appropriate choice. It is also important for partners to remember that when they bring their personal distress into the marital arena, it may become a marital stress as well.

Help couples to understand that it may be detrimental to raise marital complaints when the partner is in distress. Keeping personal distress separate from marital complaints may help couples improve both their conflict resolution skills and their social support skills. This may not always be easy for couples because how a partner handles his or her individual distress can have 
an impact on the spouse, much more so than a friend or another relation. For example, if a spouse talks to a friend about whether on not to quit her very stressful job, the friend may help her weigh the pros and cons and offer support for whatever decision is made. If, however, she talks to her partner about it, he may not be able to be as supportive about leaving the job, because of the potential impact on his own financial security. Sometimes, therefore, it might be very important to separate the spouse's personal issue from potential marital issues and understand both, especially when a major decision needs to be made. Understanding your spouses’ personal position and why it is important to them can be an important first step toward tackling the marital disagreement and trying to resolve it

Help couples to see that advice is usually not helpful, while emotional support often is. Although practical suggestions may sometimes be useful, simply giving advice, especially without regard to the emotional aspect of the partner's distress can often be experienced as dismissive and negative. Couples who tend to give a lot of unsolicited advice will probably end up more distressed than couples who spend more time on emotional support and validation.

Help spouses to see that the times when they are least likely to seek support may be the

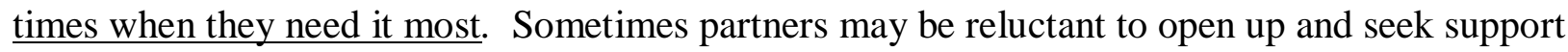
when they are feeling distressed. They may feel it is too risky to put themselves in a vulnerable position when they are already feeling badly, or they may hope their distress will just go away. Research indicates, however, that being skillful in seeking emotional support when in distress is a positive indicator for keeping a marriage happy. It may be helpful to remind partners that they do need their partner's support when they are in distress.

$\underline{\text { Specific strategies for working with couples }}$

Assessment. As with conflict resolution skills, a careful assessment of couples' social 
support skills at the beginning of treatment is important. Couples' abilities to ask for and receive help from one another may be assessed by asking couples specifically about how they handle situations in which one of them is distressed or by direct observation within the session. When inquiring about behavior outside of treatment, it is usually best to ask about specific situations in which one partner needed support. As couples describe an interaction, the therapist can observe how the distressed partner successfully or unsuccessfully approached his or her partner and how effective the helping partner's response was. For direct observation, a therapist can ask one of the partners to talk about some personally distressing situation and observe how this information is presented and how the spouse responds. A careful assessment not only gives the clinician information about what the couple needs to learn, but also gets the couple to start thinking about the nature of support in their relationship and how it might be enhanced.

Intervention. Debriefing support interactions that occur outside the session and encouraging support interactions within the session are also useful tools for continued intervention. We find it particularly helpful to stop spouses, either during the interaction or while debriefing it, and encourage them to consider other options in responding to their partner. What could they have said or done differently, and how would this have affected their partner? Encourage the partner to help identify responses that would have been more helpful to him or her, and how the initial response made them feel. Use of this technique over time may be helpful in several ways. First, it may increase spouses’ ability to actively choose effective responses instead of just automatically reacting. Second, it will increase spouses’ repertoire of possible responses and awareness of how different responses affect their partner differently. Third, the actual experience of receiving and giving better support in the session may be one of the most powerful ways to change spouses behavior. 
Make use of general communication and problem-solving techniques that have traditionally been used to help couples with conflict. As demonstrated by the research outlined earlier, the problems that occur when spouses are trying to support one another may be similar to problems that arise in conflict discussions. Therefore, good general communication skills, such as paraphrasing, listening actively and empathetically, speaking clearly and disclosing should also be effective in helping couples enhance their support skills. Couples need to be shown how use of these techniques will help them have good support discussions as well as good conflict discussions, and that they need to invoke these skills not only when they are experiencing conflict but also when one of them is in personal distress.

Finally help couples to realize that regular attendance to the importance of support in their marriage will help them to prevent many of the conflicts that are so distressing to them. A homework assignment may be particularly helpful here. Have spouses find a comfortable way to attend to any personal distress they might have experienced during the day relatively soon after they get home for the evening. This will increase their chances of getting support for individual problems, which may increase satisfaction and decrease conflict. Then have spouses note whether the conflict around relationship problems that arose over the course of the evening was reduced, especially compared to evenings when they withdrew or took their distress out on their partner. Once couples experience the preventative power of ongoing support in marriage, they will be much more likely to continue to pay attention to the importance of social support to their relationship. 


\section{References}

Bradbury, T.N., \& Fincham, F.D. (1990). Attributions in marriage: Review and critique. Psychological Bulletin,107, 3-33.

Bradbury, T.N., \& Fincham, F.D. (1991). A contextual model for advancing the study of marital interaction. In G.J.O. Fletcher \& F.D. Fincham (Eds) Cognition in close relationships (pp. 127-147). Hillsdale, N.J.: Erlbaum.

Bradbury, T.N., \& Pasch, L.A. (1992). The Social Support Interaction Coding System. Unpublished coding manual. University of California, Los Angeles.

Cutrona, C.E., \& Suhr, J.A. (1994). Social support communication in the context of marriage: An analysis of couples’ supportive interactions. In B.Burleson, T. Albrecht, \& I. Sarason (Eds.), The communication of social support: Messages, interactions, and community. (pp. 113-135). Thousand Oaks, CA: Sage.

Cutrona, C.E. (1996). Social support in couples. Thousand Oaks, CA: Sage.

Hahlweg, K., Braunschweig, T.U., Thurmair, F., Eckert, J., Engel, J., \& Markman, H.J. (1996, November). The Munich EPL Premarital Prevention Study: Results of the 5 year followup. Paper presented at the conference of the Association for Advancement of Behavioral Therapy, New York, N.Y.

Gottman, J.M., \& Krokoff, L.J. (1989). Marital interaction and satisfaction: A longitudinal view. Journal of Consulting and Clinical Psychology, 57, 47-52.

Jacobson, N.S. \& Margolin, G. (1979). Marital therapy: Strategies based on social learning and behavior exchange principles. New York: Brunner/Mazel.

Karney, B.R., \& Bradbury, T.N. (1995). The longitudinal course of marital quality and stability: A review of theory, method, and research. Psychological Bulletin, 118, 3-34. 
Koerner, K., \& Jacobson, N.S. (1994). Emotion and behavioral couple therapy. In S.M. Johnson \& L.S. Greenberg (Eds) The heart of the matter: Perspectives on emotion in marital therapy (pp. 207-226). New York: Brunner/Mazel.

Locke, H. \& Wallace, K. (1959). Short marital adjustment and prediction tests: Their reliability and validity. Marriage and Family Living, 21, 251-255.

Markman, H.J. (1981). Prediction of marital distress: A 5-year follow-up. Journal of Consulting and Clinical Psychology, 49, 760-762.

Pasch, L.A., \& Bradbury, T.N. (1998). Social support, conflict, and the development of marital dysfunction. Journal of Consulting and Clinical Psychology, 66, 219-230.

Weiss, R.L., \& Heyman, R.E. (1990). Observation of marital interaction. In F.D. Fincham \& T.N. Bradbury (Eds.) The psychology of marriage. (pp. 87-119). New York: Guilford. 


\section{Author Notes}

Kieran Sullivan is an assistant professor at the Department of Psychology, Santa Clara University. Lauri Pasch is an assistant professor at the Department of Pediatrics, University of California, San Francisco. Kathleen Eldridge and Thomas Bradbury are at the Department of Psychology, University of California, Los Angeles, where Dr. Bradbury is an associate professor. This research was funded by National Research Service Award MH10779 to Kieran Sullivan and NIMH Grant MH48674 to Thomas Bradbury. Correspondence concerning this article should be addressed to Kieran Sullivan, Ph.D., Department of Psychology, Santa Clara University, Santa Clara, CA 95053. Address electronic mail to: ksullivan@mailer.scu.edu or bradbury@psych.ucla.edu. For more information about the UCLA Project on Newlywed Behavior and Adult Development, visit website: http//www.lifesci.ucla.edu/psych/Resources/ newed/tom.htm. 


\section{Footnotes}

${ }^{1}$ Polytomous logistic regression was used to determine whether behavior at Time 1 affected the odds of being in a particular group at Time 2 (distressed, satisfied, very satisfied). In order to provide a conservative test, Time 1 MAT scores were entered as control variables in the logistic regression models. Readers interested in additional methodological and analytic detail are referred to Pasch and Bradbury (199 ) 


\section{Figure Captions}

Figure 1. Mean number of incidences of positive and negative affect codes, for husbands and for wives, in relation to 24-month marital outcome.

Figure 2. Mean proportions of positive and negative Helpee behaviors, for husbands and for wives, in relation to 24-month marital outcome.

Figure 3. Mean proportions of positive and negative Helper behaviors, for husbands and for wives, in relation to 24-month marital outcome. 
April 9, 1998

Jon Carlson, Ph.D.

Editor, The Family Journal

Lake Geneva Wellness Clinic

101 Broad Street

Lake Geneva, WI 53147

Dear Dr. Carlson,

Thank you for your letter of acceptance for our manuscript "Social Support in Marriage:

Translating Research into Practical Applications for Clinicians” by myself, Drs. Pasch and Bradbury, and Kathy Eldridge. We are very excited that the manuscript will be published in The Family Journal. Enclosed is the final copy of the manuscript as well as a copy on diskette. I have also included my Author Information Form and my signed agreement with Sage

Publications. These forms have been forwarded to the other authors, who have agreed to fax you their completed forms directly.

As always, please call or email with any questions or concerns: phone (408) 554-4480, email ksullivan@mailer.scu.edu.

Once again, we appreciate your ongoing assistance in this manner.

Sincerely,

Kieran Sullivan, Ph.D. 